\title{
Integrated X-ray L Absorption Spectra. Counting Holes in Ni Complexes
}

\author{
Hongxin Wang,,$^{\dagger}$, Pinghua Ge $^{\S}$ C. G. Riordan, ${ }^{\S}$ S. Brooker,,$\|$ C. G. Woomer, ${ }^{\perp}$ T. Collins,,$\stackrel{\perp}{ }$ \\ C. A. Melendres, ${ }^{\otimes}$ O. Graudejus, ${ }^{\circ}$ N. Bartlett, ${ }^{\circ}$ and S. P. Cramer $*,+$, \\ Department of Applied Science, University of California, Davis, California 95616, Structural Biology Division, \\ Lawrence Berkeley National Laboratory, Berkeley, California 94720, Department of Chemistry and \\ Biochemistry, University of Delaware, Newark, Delaware 19716, Department of Chemistry, University of \\ Otago, P.O. Box 56, Dunedin, New Zealand, Department of Chemistry, Carnegie Mellon University, \\ Pittsburgh, Pennsylvania 15213, Materials Science and Chemical Technology Division, Argonne National \\ Laboratory, Argonne, Illinois 60439, and Department of Chemistry, University of California, \\ Berkeley, California 94720
}

Received: April 30, 1998; In Final Form: July 21, 1998

\begin{abstract}
Despite the fact that chemists frequently draw electron density distributions, there are few good methods for measuring this quantity, which has contributed to many longstanding controversies in chemistry. In this paper, we report the first application of element specific L absorption spectra and the "white light" sum rule to a series of nickel complexes, with wide oxidation state range from $\mathrm{Ni}^{\mathrm{I}}$ to $\mathrm{Ni}^{\mathrm{IV}}$. Nickel $\mathrm{L}$ edge $\mathrm{X}$-ray absorption spectroscopy is turning out to be an excellent quantitative probe of $3 \mathrm{~d}$-vacancies.
\end{abstract}

\section{Introduction}

The distribution of electron density in inorganic complexes determines their chemical and physical properties. Difficulty in quantitatively measuring electron density distributions has contributed to many longstanding controversies, such as the oxidation states of $\mathrm{Fe}$ in oxyhemoglobin and catalase, of $\mathrm{Cu}$ in cytochrome oxidase, or of $\mathrm{Mn}$ in the oxygen-evolving complex. ${ }^{1,2}$ The best description of the Ni oxidation state in various materials is also frequently debated. This has been true for the doped system $\mathrm{Li}_{x} \mathrm{Ni}_{1-x} \mathrm{O}_{2},{ }^{3}$ for $\mathrm{Ni}$ with noninnocent ligands such as dithiolenes, ${ }^{4}$ and for the assignments of EPR signals, and hence oxidation states, of $\mathrm{Ni}$ in the $\mathrm{Ni}-\mathrm{Fe}$ hydrogenases..$^{5-7}$ There is also interest in the electronic structure of high-valent nickel species,${ }^{8-13}$ some of which may be intermediates in catalytic oxidations, ${ }^{14,15}$ and Ni-mediated site specific cleavage of DNA by coordination compounds ${ }^{16-18}$ or metalloproteins. ${ }^{19,20}$

There are surprisingly few methods for directly measuring electron density distributions, and most techniques that purport to do so are based on empirical correlations. In some cases, electron density distributions can be measured with very high accuracy diffraction data; X-ray studies of $4 \mathrm{f}$ electron density in $\mathrm{CeB}_{6}{ }^{21}$ and $3 \mathrm{~d}$ density in $\mathrm{Ni}\left(\mathrm{ND}_{3}\right)_{4}\left(\mathrm{NO}_{2}\right)_{2}{ }^{22}$ are recent examples. Spin density distributions are also recoverable from magnetic resonance measurements. However, in most cases, diffraction techniques cannot provide sufficient accuracy for determining electron distributions to within a fraction of an electron, and many solid-state problems are not amenable to magnetic resonance studies.

In X-ray spectroscopy there is a sum rule stating that the integrated intensity for a particular absorption edge reflects the

\footnotetext{
* To whom correspondence should be addressed

University of California, Davis.

$\doteqdot$ Lawrence Berkeley National Laboratory.

$\S$ University of Delaware.

"University of Otago.

${ }^{\perp}$ Carnegie Mellon University.

$\otimes$ Argonne National Laboratory.

O University of California, Berkeley.
}

total number of empty states with the proper symmetry. ${ }^{23}$ For $\mathrm{K}$ edges, which involve a $1 \mathrm{~s}$ initial state, the final states have p symmetry. Edge integration has thus been used to quantify the number of oxygen p-type holes in high Tc superconductors $^{24-26}$ and transition metal oxides. ${ }^{27}$ For $\mathrm{L}_{2,3}$ edges that have an initial $\mathrm{p}$ level, the transitions are primarily to states of $\mathrm{d}$ symmetry, since the $2 \mathrm{p} \rightarrow 4$ s transitions are $\sim 20$-fold weaker. ${ }^{28} \mathrm{~L}$ edge intensities have been used to quantify charge transfer in platinum ${ }^{29}$ or iridium catalysts, ${ }^{30}$ in superconductors, ${ }^{25}$ and in blue copper proteins. ${ }^{31}$ We report here the first integrated $\mathrm{L}$ edge measurements for a series of $\mathrm{Ni}$ complexes in different oxidation states.

$\mathrm{Ni} \mathrm{L}_{2,3}$ edges involve resonances or "white lines" that are $2 \mathrm{p}$ $\rightarrow 3 \mathrm{~d}$ transitions, along with much weaker $2 \mathrm{p} \rightarrow 4 \mathrm{~s}$ transitions,

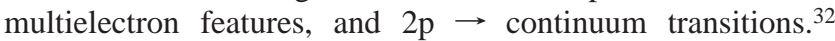
Transition metal white lines were first observed by Cauchois and Bonnelle about 40 years ago, ${ }^{33,34}$ but the advent of highbrightness synchrotron radiation sources ${ }^{35}$ and high-resolution beamline optics ${ }^{36}$ has revolutionized spectroscopy in this region. The positions, branching ratio, and multiplet splittings of $\mathrm{Ni} \mathrm{L}$ edge spectra have already been used to characterize battery materials, ${ }^{37,38}$ coordination complexes, ${ }^{39-41}$ and enzymes. ${ }^{41,42}$ However, apart from $\mathrm{Ni}$ metal, ${ }^{28}$ the integrated intensity of these transitions has been ignored.

\section{Experimental Section}

$\mathrm{Na}\left[\mathrm{Ni}^{\mathrm{I} \text { " }} \mathrm{S}_{4}\right.$ "] ${ }^{43}$ and $\left[\mathrm{Ni}^{\mathrm{I} \text { " }} \mathrm{N}_{4}\right.$ "] $\mathrm{CF}_{3} \mathrm{SO}_{3}{ }^{44}$ and their $\mathrm{Ni}^{\mathrm{II}}$ counterparts were prepared according to the cited literature procedures $^{43,44}$ described by Riordan and co-workers. The abbreviation " $\mathrm{N}_{4}$ " represents 1,4,8,11-tetraazacyclotetradecane and "S${ }_{4}$ " represents bis(diphenylbis((methylthio)methyl)borate). $\left[\mathrm{Ni}_{2}{ }^{\mathrm{II}}\right.$ "LS1"] $\left(\mathrm{ClO}_{4}\right)_{2}$ was prepared in the Brooker lab. ${ }^{44}$ "LS1" represents the macrocyclic ligand derived from $2+2$ condensation of 2,6-diformyl-4-methyl-thiophenolate and 1,3-diaminopropane. $\mathrm{Ni}^{\mathrm{II}} \mathrm{F}_{2}$ and $\mathrm{K}_{3} \mathrm{Ni}^{\mathrm{III}} \mathrm{F}_{6}{ }^{46}$ were prepared in the Bartlett lab. $\mathrm{Li}\left[\mathrm{Ni}^{\mathrm{III}}\left(\kappa^{4}-\mathrm{mac}^{*}\right)\right]$, where $\left(\kappa^{4}-\mathrm{mac}^{*}\right)$ is peralkylated(*) macrocyclic polyanionic chelating ligand $=13,13$-diethyl- 
2,2,5,5,7,7,10,10-octamethyl-3,6,9,12,14-pentaoxo-1,4,8,11-tetraazacyclotetradecane, was synthesized in the Collins lab according to literature procedures. ${ }^{47} \mathrm{KNi}^{\mathrm{IV}} \mathrm{IO}_{6}$ was prepared in the Melendres lab. ${ }^{48}$ Finely powdered compounds were spread across and pressed onto a piece of Teflon tape, which was attached to the sample holder by a double-stick tape.

Absolute cross sections in the soft X-ray region are difficult to measure. For transmission measurements the proper thickness is only a few thousand angstroms, and homogeneous samples are difficult to prepare. The spectra were therefore recorded in electron yield mode. ${ }^{49}$

L edge spectra were measured using the UC/LLNL beamline $8-2^{50,51}$ at the Stanford Synchrotron Radiation Lab (with $60 \mu \mathrm{m}$ slits, corresponding to $0.8 \mathrm{eV}$ energy resolution at $853 \mathrm{eV}$ ). The total electron yield from model complexes $\left(I_{\mathrm{E}}\right)$ was measured using a Galileo 4716 channeltron electron multiplier; the incident beam intensity $\left(I_{0}\right)$ was measured as the photocurrent through a gold-plated grid to obtain the raw spectra $\left(I_{\mathrm{E}} / I_{0}\right)$. The sample chamber was maintained at a vacuum of $2 \times 10^{-9}$ Torr or better, enabling windowless operation between the storage ring, sample, and detector. Spectra were calibrated using the $\mathrm{L}_{3}$ peak position of $\mathrm{NiF}_{2}$, with the absorption maximum assigned arbitrarily as $852.7 \mathrm{eV}$. The spectra are reproducible to $0.1 \mathrm{eV}$, although the absolute calibration may not be correct.

The basic L edge data processing involved subtraction of a baseline for blank sample and the normalization of the spectra to achieve a continuum intensity of unity and to study the integrated $\mathrm{L}$ intensities on the same scale. The $\mathrm{L}_{3}$ and $\mathrm{L}_{2}$ integrated intensities were then obtained by integration over $851-858$ and $868-875 \mathrm{eV}$, respectively. The spectra analysis also includes subtraction of a polynomial function representing the non L edge (nonresonant) absorption background to get pure resonance (flat) spectra. The $\mathrm{L}_{3}$ and $\mathrm{L}_{2}$ centroids were obtained from these spectra.

\section{Results and Discussion}

In Figure 1, we present spectra for $\mathrm{Ni}$ in different oxidation states, from $\mathrm{Ni}^{\mathrm{I}}$ to $\mathrm{Ni}^{\mathrm{IV}}$. $\mathrm{Ni}^{\mathrm{I}}{ }^{\text {" }} \mathrm{S}_{4}$ " and $\mathrm{Ni}^{\mathrm{I}}{ }^{\text {" }} \mathrm{N}_{4}$ " have $3 \mathrm{~d}^{9}$ configurations and should have relatively small $2 \mathrm{p} \rightarrow 3 \mathrm{~d}$ resonance transition when normalized to the nonresonant $2 \mathrm{p} \rightarrow$ outgoing d wave continuum transitions, as is indeed observed in Figure 1. As the oxidation state increases, from $\mathrm{Ni}^{\mathrm{II}}$ to $\mathrm{Ni}^{\mathrm{III}}$ to $\mathrm{Ni}^{\mathrm{IV}}$, the number of $\mathrm{d}$ holes increases; hence, the $\mathrm{L}$ edge resonance intensity should also increase. This is indeed observed, most dramatically for $\mathrm{KNi}^{\mathrm{IV}} \mathrm{IO}_{6}$ (Figure 1).

The qualitative trend for $\mathrm{L}$ edge intensities to increase with Ni oxidation states is not a surprise. However, it is gratifying to see that the integrated values agree quantitatively with the expected number of holes. Since absolute cross sections are difficult to obtain in this region, we have normalized the spectra by assuming that the average cross section per $\mathrm{Ni}$ is invariant at about $950 \mathrm{eV}$. As shown in Figure 2, with spectra normalized in this fashion, there is an almost linear dependence of integrated white line intensity on $\mathrm{Ni}$ oxidation state.

To put our measurements on an absolute scale, we need either (a) a standard material for which the number of holes is accurately known or (b) a theoretical spectrum calculation of the normalized edge area for a sample with a fixed number of holes. At the moment, only the former is available. Stöhr has reported and analyzed the $\mathrm{Ni}$ metal as L edge spectrum. ${ }^{52,53}$ Using our procedure, we find a normalized white line intensity of 13.1 for this spectrum. Given the band structure value of $\sim 1.5$ for the number of holes, ${ }^{52,53}$ we find that a normalized area of 8.66 corresponds to one hole by our method. The

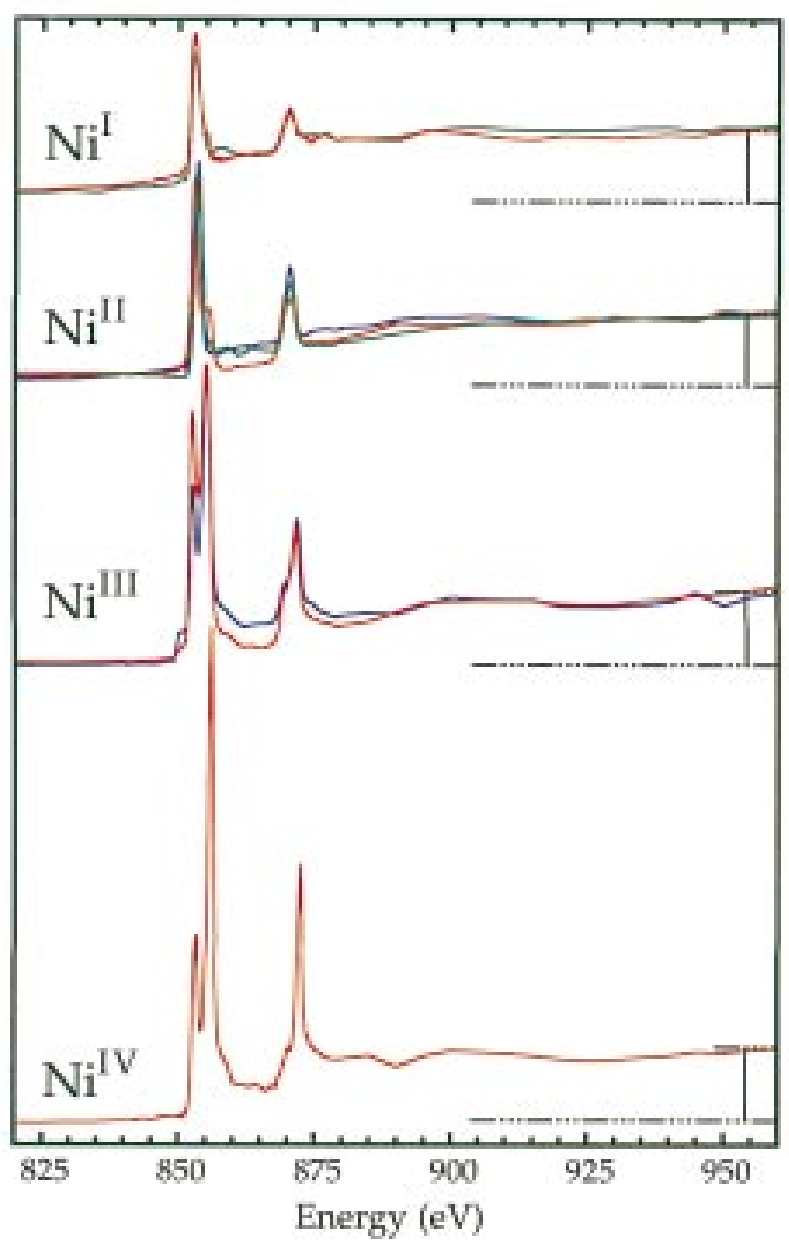

Figure 1. Comparison of normalized L edges absorption spectra of $\mathrm{Ni}$ complexes. From top to bottom: (1) $\mathrm{Na}\left[\mathrm{Ni}^{\mathrm{I}}\right.$ " $\mathrm{S}_{4}$ "] (green) and $\mathrm{Na}\left[\mathrm{Ni}^{\mathrm{I}}\right.$ "N $\mathrm{N}_{4}$ "] (red); 2) [ $\mathrm{Ni}^{\mathrm{II}}{ }_{2}$ "LS1"] (blue), $\mathrm{Ni}^{\mathrm{II}} \mathrm{F}_{2}$ (red), and

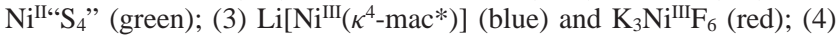
$\mathrm{KNi}^{\mathrm{IV}} \mathrm{IO}_{6}$ (red).

number of $\mathrm{d}$ holes in the current set of compounds can thus obtained, and the absolute number of holes has been included as an alternate scale for the ordinate in Figure 2 (right axis). Since different band structure calculations differ by $\sim 0.2$ in the number of holes, ${ }^{54}$ the calculated values have an error on the order of $15-20 \%$, and when $\sim 10 \%$ experimental errors are also considered, this intensity-to-3d holes conversion ratio (8.66) and thus the alternate right axis can have an uncertainty of about $25 \%$.

We find that the predicted number of holes in our set of compounds is, on average, $79 \%$ of the value implied by blind application of the formal oxidation state. In the current data set, the closest approach to the $100 \%$ ionic value was for $\mathrm{K}_{3}$ $\mathrm{NiF}_{6}$, with 2.8 holes from the $\mathrm{X}$-ray data vs 3.0 for a pure $\mathrm{Ni} \mathrm{iII}^{\mathrm{II}}$ $3 \mathrm{~d}^{7}$ configuration. The greatest deviation from the purely ionic value was for $\mathrm{Ni}^{\mathrm{I}}$ " $\mathrm{S}_{4}$ ", with $65 \%$ of the 1.0 hole predicted for $3 \mathrm{~d}^{9} \mathrm{Ni}^{\mathrm{I}}$. As expected, the $\mathrm{S}$ donor complexes had lower ionicity than complexes with more electronegative $\mathrm{N}$, O, or $\mathrm{F}$ ligands. As a quantitative measure of the number of $3 \mathrm{~d}$ doles on a transition metal, this method should be broadly applicable to a number of issues in inorganic chemistry.

Of course, there is considerably more information in the spectra than just the integrated intensity. The centroid energies, branching ratios, and multiplet structure are all sensitive to electronic structure. ${ }^{32}$ As shown in Figure 3, the energies of the Ni $2 p \rightarrow 3 d$ centroids shift to higher energy with increasing 


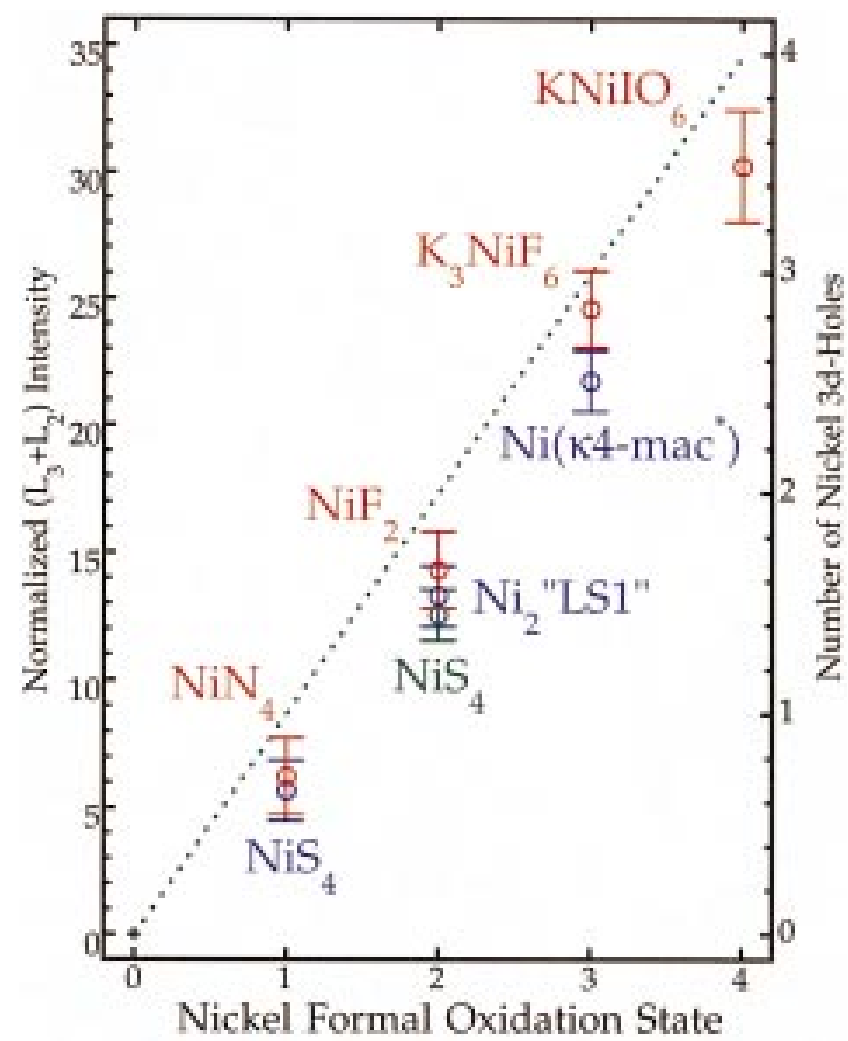

Figure 2. Integrated intensity of the L edge resonance, normalized to the nonresonance absorption background, as a function of formal oxidation state (I, II, III, IV). The dotted green line represents our best estimate for the purely ionic limit, using an 8.66:1 intensity-to-3d holes conversion ratio (where $\mathrm{Ni}\left(\kappa 4-\mathrm{mac}^{*}\right)$ is $\mathrm{Li}\left[\mathrm{Ni}\left(\kappa^{4}-\mathrm{mac}^{*}\right)\right]$.

oxidation state. In many cases, measurement of the L edge position will suffice for oxidation-state assignments. However, shifts in the position of these peaks correspond to energy changes in the final state energies, while the integrated transition intensity is a ground-state property. ${ }^{33,34}$ Therefore, L edge integration is a more quantitative and direct measure of $\mathrm{d}$ shell vacancies in the ground state. Also, the ligand field splittings of the d orbitals, and the multiplets of the Ni L edge, are sensitive to bond lengths, molecular geometry, and spin state. Analysis of the details of the fine structure needs to utilize ligand field multiplet theory and configuration interaction and the calculations will be reported elsewhere.

\section{Summary}

The intensities of $\mathrm{L}$ edge spectra of $\mathrm{Ni}$ complexes can be used to quantitatively determine the number of $3 \mathrm{~d}$ vacancies. There are many problems in inorganic chemistry that could be addressed by using X-ray sum rule analysis. For earlier transition metals than $\mathrm{Ni}$, careful measurement of the continuum transition intensity will be required. Still, with the vast improvement in synchrotron radiation sources and beamline optics, quantitative L edge spectroscopy is not extremely difficult. When the distribution of electrons in a transition metal complex is an important point in the characterization of a sample, L edge spectroscopy should be considered.

Acknowledgment. This work was supported by the NIH through GM-44380 (to S.P.C.) and through GM-44867 (to T.C.), and the Department of Energy, Office of Biological and Environmental Research. We thank Paul D. Croucher and Geoffrey S. Dunbar (University of Otago) for preparing samples

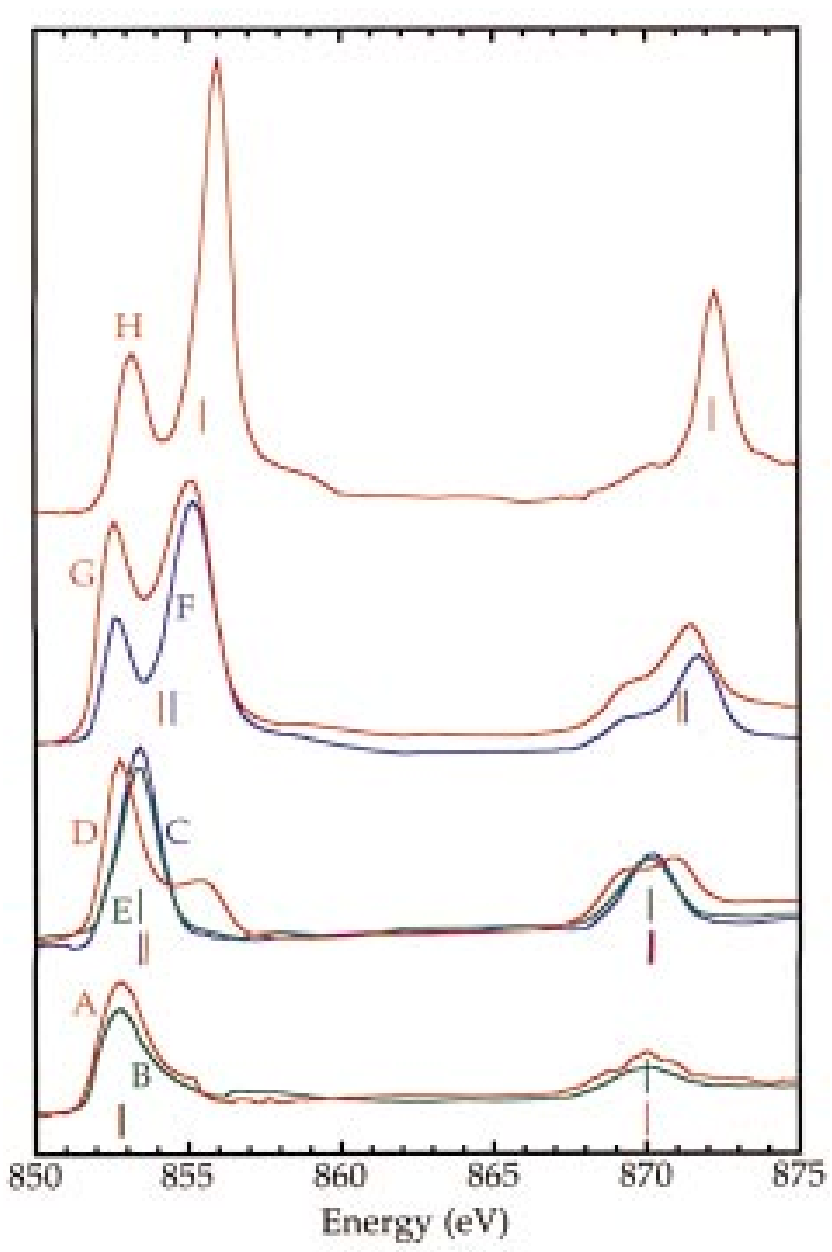

Figure 3. Expanded L edge multiplets (solid lines) along with $\mathrm{L}_{3}$ and $\mathrm{L}_{2}$ centroids (vertical bars with letters) for Ni complexes. From top to bottom: (1) $\mathrm{KNi}^{\mathrm{IV}} \mathrm{IO}_{6}$ (red, $\mathrm{H}$ ); (2) $\mathrm{K}_{3} \mathrm{Ni}^{\mathrm{III}} \mathrm{F} 6$ (red, G) and $\mathrm{Li}\left[\mathrm{Ni}^{\mathrm{III}}\right.$ $\left.\left(\kappa^{4} \mathrm{mac}^{*}\right)\right]$ (blue, F); (3) $\mathrm{Na}\left[\mathrm{Ni}^{\mathrm{II}}\right.$ " $\mathrm{S}_{4}$ "] (green, E), $\mathrm{Ni}^{\mathrm{II}} \mathrm{F}_{2}$ (red, D) and [Ni" ${ }_{2}$ "LS1"] (blue, C); (4) $\mathrm{Na}\left[\mathrm{Ni}^{\mathrm{i}}\right.$ " $\mathrm{S}_{4}$ "] (green, $\mathrm{B}$ ) and $\mathrm{Na}\left[\mathrm{Ni}^{\mathrm{II} "} \mathrm{~N}_{4}\right.$ "] (red, A).

of $\left[\mathrm{Ni}_{2}{ }\right.$ "S ${ }_{1}$ "] $\left(\mathrm{ClO}_{4}\right)_{2}$. We are grateful to Dr. J. Stöhr for the Ni metal spectrum as well as valuable discussions, and we thank Prof. T. D. P. Stack and his student Y. Wang for the permit and assistance in use of his laboratory during our work at SSRL. SSRL is supported by the Department of Energy, Office of Basic Energy Sciences.

\section{References and Notes}

(1) Lippard, S. J.; Berg, J. M. In Principles of Bioinorganic Chemistry; University Science Books: Mill Valley, CA, 1994.

(2) Bertini, I.; Gray, H. B.; Valentine, J. S. In Bioinorganic Chemistry; University Science Books: Mill Valley, CA, 1994.

(3) Pickering, I. J.; George, G. N.; Lewandowski, J. T.; Jacobson, A J. J. Am. Chem. Soc. 1993, 115, 4137.

(4) Coyle, C. L.; Stiefel, E. I. In The Bioinorganic Chemistry of Nickel; Lancaster J. R., Jr., Ed.); VCH Publishers: New York, 1988; pp 1-28.

(5) Cammack, R.; Fernandez, V.; Hatchikian, E. C. In Methods in Enzymology, Inorganic Microbial Sulfur Metabolism; Academic Press Inc.: San Diego, CA, 1994; Vol. 243, pp 43-67.

(6) Albracht, S. P. J. Biochim. Biophys. Acta 1994, 1188, 167.

(7) Huyett, J. E.; Carepo, M.; Pamplona, A.; Franco, R.; Moura, I.; Moura, J. J. G.; Hoffman, B. M. J. Am. Chem. Soc. 1997, 116, 9291.

(8) Sacconi, L.; Mani, F.; Bencini, A. In Comprehensive Coordination Chemistry Wilkinson, G., Guillard, R. D., McCleverty, J. A., Eds.; Pergamon Press: New York, 1987.

(9) Nag, K.; Chakravorty, A. Coord. Chem. Rev. 1980, 33, 87

(10) Lappin, G.; McAuley, A. Adv. Inorg. Chem. 1988, 32, 241

(11) McAuley, A.; Palmer, T.; Whitcombe, T. W. Can. J. Chem. 1993, 71,1792 .

(12) Haines, R. I.; McAuley, A. Coord. Chem. Rev. 1981, 39, 77. 
(13) McAuley, A.; Fortier, D. G.; Macartney, D. H.; Whitcombe, T.

W.; Xu, C. J. Chem. Soc., Dalton Trans. 1994, 2071.

(14) Yoon, H.; Burrows, C. J. J. Am. Chem. Soc. 1988, 110, 4087.

(15) Yoon, H.; Wagler, T. R.; O'Connor, K. J.; Burrows, C. J. J. Am. Chem. Soc. 1990, 112, 4568.

(16) Muller, J. G.; Chen, X.; Dadiz, A. C.; Rokita, S. E.; Burrows, C. J. J. Am. Chem. Soc. 1992, 114, 6407.

(17) Muller, J. G.; Chen, X.; Dadiz, A. C.; Rokita, S. E.; Burrows, C. J. Pure Appl. Chem. 1993, 65, 545.

(18) Cheng, C. C.; Rokita, S. E.; Burrows, C. J. Angew. Chem. Int. Ed. Engl. 1993, 32, 277.

(19) Mack, D. P.; Dervan, P. B. J. Am. Chem. Soc. 1990, 112, 4604

(20) Mack, D. P.; Dervan, P. B. Biochemistry 1992, 31, 9399.

(21) Tanaka, K.; Kato, Y.; Onuki, Y. Acta Crystallogr. B 1997, 53, 143.

(22) Iversen, B. B.; Larsen, F. K.; Figgis, B. N.; Reynolds, P. J. Chem.

Soc. Dalton Trans. 1997, 2227.

(23) Starace, A. F. Phys. Rev. B 1972, 5, 1773

(24) Fink, J.; Nucker, N.; Romberg, H.; Alexander, M.; Knupfer, M. J. Electron Spectrosc. Relat. Phenom. 1994, 66, 395.

(25) Chen, J. M.; Liu, R. S.; Liang, W. Y. Phys. Rev. B 1996, 54, 12587.

(26) Pellegrin, E.; Fink, J.; Chen, C. T.; Xiong, Q.; Lin, Q. M.; Chu, C.

W. Phys. Rev. B 1996, 53, 2767.

(27) Degroot, F. M. F.; Grioni, M.; Fuggle, J. C.; Ghijsen, J.; Sawatzky,

G. A.; Petersen, H. Phys. Rev. B 1989, 40, 5715.

(28) Stöhr, J. J. Electron Spectrosc. Relat. Phenom. 1995, 75, 253.

(29) Horsley, J. A. J. Chem. Phys. 1982, 76, 1451.

(30) Deutsch, S. E.; Mestl, G.; Knozinger, H.; Gates, B. C. J. Phys. Chem. B 1997, 101, 1374.

(31) George, S. J.; Lowery, M. D.; Solomon, E. I.; Cramer, S. P. J. Am. Chem. Soc. 1993, 115, 2968

(32) deGroot, F. M. F. J. Electron Spectrosc. Relat. Phenom. 1994, 67, 529

(33) Cauchois, Y.; Bonnelle, C. C. R. Acad. Sci. Paris 1957, 245, 1230

(34) Bonnelle, C. C. R. Acad. Sci. Paris 1959, 248, 2324.

(35) Schlacter, A. S. In New Directions in Research with ThirdGeneration Soft X-ray Synchrotron Light Sources; Schlacter, A. S., Wuilleumier, F. J., Eds.; Kluwer Academic Publishers: Dordrecht, 1994; pp $1-22$.
(36) Chen, C. T.; Sette, F. Rev. Sci. Instrum. 1989, 60, 1616.

(37) van Elp, J.; Eskes, H.; Kuiper, P.; Sawatzky, G. A. Phys. Rev. B 1992, 45, 1612 .

(38) van Veenendaal, M. A.; Sawatzky, G. A. Phys. Rev. B 1994, 50, 11326

(39) van der Laan, G.; Thole, B. T.; Sawatzky, G. A.; Verdaguer, M. Phys. Rev. B 1988, 37, 6587.

(40) van Elp, J.; Peng, G.; Searle, B. G.; Mitra-Kirtley, S.; Huang, Y. H.; Johnson, M. K.; Zhou, Z. H.; Adams, M. W. W.; Maroney, M. J.; Cramer, S. P. J. Am. Chem. Soc. 1994, 116, 1918.

(41) Ralston, C.; Chen, J.; Peng, G.; George, S. J.; van Elp, J.; Cramer, S. P. Physica B 1995, 209, 203.

(42) van Elp, J.; Peng, G.; Zhou, Z. H.; Adams, M. W. W.; Baidya, N.; Mascharak, P. K.; Cramer, S. P. Inorg. Chem. 1995, 34, 2501.

(43) Ge, P. H.; Riordan, C. G.; Yap, G. P. A.; Rheingold, A. L. Inorg. Chem. 1996, 35, 5408.

(44) Ram, M. S.; Riordan, C. G.; Ostrander, R.; Rheingold, A. L. Inorg Chem. 1995, 34, 5884.

(45) Brooker, S.; Croucher, P. D.; Roxburgh, F. M. J. Chem. Soc. Dalton Trans. 1996, 3031.

(46) Zemva, B.; Chacon, L.; Lutar, K.; Shen, C.; Allman, J.; Bartlett, N. J. Fluorine Chem. 1995, 71, 195

(47) Collins, T. J.; Nichols, T. R.; Uffelman, E. S. J. Am. Chem. Soc. 1991, 113, 4708.

(48) Mansour, A. N.; Melendres, C. A. Physica B 1995, 209, 583.

(49) Stöhr, J. NEXAFS Spectroscopy; Springer-Verlag: New York, 1992.

(50) Tirsell, K. G.; Karpenko, V. P. Nucl. Instrum. Methods A 1990. $291,511$.

(51) Terminello, L. J.; Waddill, G. D.; Tobin, J. G. Nucl. Instrum Methods A 1992, 319, 271.

(52) Eriksson, O.; Johansson, B.; Albers, R. C.; Brooks, M. S. S. Phys. Rev. B 1990, 42, 2707.

(53) Söderlind, P.; Eriksson, O.; Johansson, B.; Albers, R. C.; Boring, A. M. Phys. Rev. B 1992, 45, 12911.

(54) Gropen, O.; Almlof, J. Chem. Phys. Lett. 1992, 191, 306. 